\title{
A Estratégia de Desenvolvimento e o Programa de Integração Nacional
}

JOÃo PAULO dos REIS VELLOSO Ministro do Planejamento e Coordenação Geral

A história do desenvolvimento brasileiro no pós-guerra foi, até pouco, essencialmente, a história do desenvolvimento do Centro-Sul. O III Govêrno da Revolução, que já havia decidido consolidar Brasília como capital federal, lança agora as bases, através do Programa de Integração Nacional, para, simultânea e integradamente, acrescer duas dimensões àquele processo: a da ocupação econômica de cêrca de 2 milhões de $\mathrm{km}^{2} \mathrm{da}$ Amazônia e a da incorporação à economia de mercado de aproximadamente 13 milhões de habitantes da região semiárida do Nordeste.

A Nação brasileira entendeu o ato de decisão e coragem do Presidente Garrastazu Médici, nascido da sua insatisfação em face de soluções menores para os dois desafios - o da Amazônia e o do Nordeste - os quais, considerados isoladamente, tenderiam a perpetuar-se em tratamento de rotina. As manifestações desta Casa, pelas vozes mais autorizadas da ARENA e do MDB, na oportunidade do diálogo com os meus eminentes colegas e amigos Mário Andreazza e Costa Cavalcanti, indicam amplo apoio à sua concepção geral e a seus projetos prioritários. $\mathrm{Na}$ área de competência do Ministério do Planejamento e Coordenação Geral, procurarei, nesta exposição inicial, dar ênfase a certos aspectos do projeto da Transamazônica e à análise da indagação que tem preocupado, principalmente, alguns representantes do Nordeste, em face do esquema do financiamento estabelecido para o Programa: o benefício, para o País, do Programa de Integração Nacional não irá ser obtido à custa do Nordeste, e, em particular, do seu processo de industrialização? 
Desejo, desde logo, deixar claras as conclusões a que pretendo chegar, e que constituem definição de Govêrno do Presidente Médici, a saber: o Programa de Integração Nacional $e ́$, antes de tudo, a favor do Nordeste, do seu crescimento presente e da criação, na região, de um processo auto-sustentável de desenvolvimento; não haverá perda de recursos para - Nordeste, mas, antes, maior apoio do Govêrno Federal; não haverá perda de ritmo da industrialização; não haverá diminuição do programa do Banco do Nordeste; haverá intensificação dos dispêndios federais no Nordeste.

Antes, todavia, da análise dêsses aspectos, é importante colocar o Programa de Integração Nacional na perspectiva do plano global de Govêrno, no atual mandato presidencial. A estratégia nacional de desenvolvimento, no próximo estágio, deverá preocupar-se, fundamentalmente, com:

I - No Centro-Sul, a integração do desenvolvimento industrial acelerado com um crescimento mais rápido da agricultura, a taxas anuais de 6 a $8 \%$, para permitir uma expansão complementar de demanda, interna e externa, nos dois setores, simultâneamente, capaz de sustentar o aumento do Produto Interno Bruto (PIB) no ritmo programado de pelo menos 7 a $9 \%$ ao ano.

II - A construção de uma sólida estrutura educacional, científico-tecnológica e industrial, como base do progresso na sociedade moderna e democrática. Assim se poderá tirar o melhor proveito dos recursos humanos do País.

III - A consolidação do esfôrço realizado no período 1964/1969 quanto à infra-estrutura econômica de Energia, Transportes e Comunicações.

IV - A expansão da fronteira econômica nacional, para tirar proveito da dimensão continental do País, ampliando o mercado interno pela incorporação de novas áreas e, simultâneamente, pela melhor utilização da mão-de-obra abundante.

É, realmente, paradoxal que um país, como o Brasil, engajado num projeto nacional de desenvolvimento, desperdice dois fatôres vitais de produção: de um lado, a disponibilidade de terras férteis não exploradas, no Planalto Central, na Amazônia, no Meio-Norte, nos vales úmidos do Nordeste; de outro lado, a existência de abundante mão-de-obra não qualificada, operando a níveis muito baixos de produtividade, em diferentes regiöes, e, notadamente, na zona semi-árida do Nordeste. 
O fato de não ter o País, em maior escala, realizado a mágica de associar êsses dois fatôres abundantes deve-se, essencialmente, à necessidade de dispor de infra-estrutura de transporte que permita o deslocamento, racional e ordenado, da mão-de-obra. E à necessidade, também, de contar com os fatôres de produção complementares à terra e ao trabalho, representados pelo capital físico (instrumentos) e pelos diferentes insumos, pelo conhecimento técnico, pelo capital de giro etc., fatôres êsses que têm utilização alternativa na região mais desenvolvida do País. Daí os dois condicionantes indispensáveis à viabilidade de qualquer programa de expansão da fronteira econômica: a sua compatibilidade com os objetivos definidos para o crescimento da produção global do País e para a contenção da inflação.

\section{A REVOLUÇÃo E O NORDESTE}

$\mathrm{Na}$ década de 60 , o Brasil realizou um grande esfôrço de execução, no Nordeste, de uma política de desenvolvimento, em substituição à tradição centenária de uma política assistencial em relação aos efeitos da sêca. Êsse esfôrço está sintetizado nos Quadros I e II, que mostram os principais instrumentos e resultados daquela política, entre 1963 e 1969.

\section{QUADRO I \\ A Revolução e o Nordeste \\ Instrumentos da Política de Desenvolvimento $1964 / 1969$}

Preços constantes: Cr\$ milhões de 1970

\begin{tabular}{|c|c|c|c|c|}
\hline & APLICAÇÕES NO NORDESTE & 1963 & 1969 & $\begin{array}{c}\text { Aumento } \\
\%\end{array}$ \\
\hline & $\begin{array}{l}\text { Investimentos Públicos (Federais - Esta- } \\
\text { duais - Municipais) } \ldots \ldots \ldots \ldots \ldots \ldots \ldots\end{array}$ & 1.082 & 1.797 & 6 \\
\hline & Incentivos Fiscais $34 / 18$ (Depósitos) $\ldots$. & 66 & 778 & 1.07 \\
\hline & $\begin{array}{l}\text { Transferência de Impostos Ünicos Fe- } \\
\text { derais } \ldots \ldots \ldots \ldots \ldots \ldots \ldots \ldots \ldots \ldots \ldots \ldots \ldots\end{array}$ & 140 & 261 & 8 \\
\hline & $\begin{array}{l}\text { Transferência do Fundo de Participação } \\
\text { e do Fundo Especial ................... }\end{array}$ & $(\rightarrow)$ & 365 & $(-$ \\
\hline & Banco do Brasil - Total dos Empréstimos & 1.082 & 1.420 & 3 \\
\hline & $\begin{array}{l}\text { Banco do Nordeste }- \text { Total dos Emprés- } \\
\text { timos } \ldots \ldots \ldots \ldots \ldots \ldots \ldots \ldots \ldots \ldots \ldots \ldots \ldots\end{array}$ & & & 34 \\
\hline & BNDE - Novos Empréstimos .......... & & 256,6 & 1.26 \\
\hline & Financiamentos Externos - US\$ milhões & 17,2 & 51,3 & 19 \\
\hline
\end{tabular}




\section{QUADRO II \\ A Revolução e o Nordeste}

Resultados selecionados da Política de Desenvolvimento $1964 / 1969$

\begin{tabular}{cccc}
\hline INDICADORES & 1963 & 1969 & $\begin{array}{c}\text { Aumento } \\
\%\end{array}$ \\
\hline
\end{tabular}

1. Renda Regional - Cr\$ milhões de 1970 (aproximação preliminar) ............ 16.055

22.760

42

2. Rodovias Pavimentadas $(\mathrm{km})$

2. 290

4.684

105

3. Energia Elétrica - Potência instalada (em $1.000 \mathrm{~kW}$ )

497,9

823,4

65

4. Educação - Total de matrículas $(1.000$ matrículas)

— Ensino Primário ................ 2.224

- Ensino Médio 334

2.985 34

- Ensino Superior

20

562

As principais conquistas do período foram:

1) A transformação da industrialização no fator dinâmico principal do processo de desenvolvimento, substituindo, nesse papel, as exportações para o exterior.

2) A taxa média de crescimento anual da renda real da região na ordem de $7 \%$ ao ano, permitindo dobrar a dimensão da economia nordestina no período de existência da SUDENE.

3) $\mathrm{O}$ aumento do emprêgo industrial, a uma taxa média da ordem de $2 \%$ ao ano, na década de 60 , em comparação com uma redução anual média de $1,4 \%$ na década de 50 .

4) A construção da infra-estrutura econômica da região, através dos investimentos realizados, principalmente, pelo Govêrno Federal, que responde por cêrca de $75 \%$ do total dos investimentos públicos no Nordeste.

Sem embargo dêsses importantes resultados, devidos, principalmente, à atuação da SUDENE, do BNB e de outros órgãos do Ministério do Interior, é preciso reconhecer que o simples prosseguimento do modêlo até aqui seguido não tem condições para proporcionar ao Nordeste, na década de 70 , taxas de crescimento acima de $7 \%$ ao ano, segundo a programação dos órgãos de desenvolvimento. Nem para manter, no longo prazo, o ritmo de industrialização observado no período anterior. Nem para resolver o problema da agricultura do Nordeste. Nem, menos ainda, para resolver o problema social do 
Nordeste, principalmente na agricultura de subsistência da região semi-árida. Nem para reduzir substancialmente o impacto social das sêcas periódicas.

A verdade é que certas distorções e problemas permanecem no quadro atual do Nordeste, como sejam:

1) Não se chegou a construir uma infra-estrutura agrícola, numa região em que $60 \%$ da população dependem dêsse setor.

Analisando a experiência de desenvolvimento regional do Sul da Itália, Vera Lutz * mostra como, naquele exemplo revelador, quase duas décadas de maciços investimentos na infraestrutura e poderosos incentivos à indústria foram insuficientes para criar um processo auto-sustentável de desenvolvimento, pela ausência de complementação setorial, face ao insatisfatório desempenho da agricultura, que, numa zona de alta densidade demográfica, logo passou a constituir limitação à própria taxa de crescimento industrial.

Daí a insuficiência de um modêlo, no Nordeste, que se limitasse ao fator dinâmico realmente bem sucedido na década de 60 - a industrialização. E o sistema de incentivos fiscais não se revelou apto a realizar a transformação da agricultura no Nordeste, que continua registrando baixa produtividade e alta vulnerabilidade ao fenômeno da sêca.

2) A industrialização, por outro lado, se representa importante contribuição ao aumento da renda e ao processo de crescimento econômico, não teve condições de resolver o problema do emprêgo da mão-de-obra, seja na área urbana, seja, principalmente, na área rural. Como se tem observado, pelo elevado subsídio que representa ao fator capital, o incentivo fiscal representa estímulo maior às indústrias intensivas de capital, em comparação com as intensivas de trabalho, e às grandes e médias emprêsas, em comparação com as pequenas emprêsas.

Em seu relatório de 1969, o Banco do Nordeste conclui: "Não obstante as 130 mil novas ocupações projetadas até junho de 1969, parece pouco provável que o setor industrial se capacite a resolver o atual problema de desocupação efetiva e disfarçada da mão-de-obra." Se, como sugere recente pesquisa de técnicos daquela instituição, a desigualdade na distri-

"Vera Lutz, "Italy - A Study in Economic Development" (principalmente o capítulo VII.) 
buição da renda do Nordeste urbano teria tendido a agravarse, nos anos 60 , a explicação poderia residir na acumulação de mão-de-obra subempregada, pela insuficiência das oportunidades de emprêgo mais produtivo.

No tocante à zona rural, o presidente da mesma instituição, em pronunciamento nesta Casa, já havia assinalado que, não obstante o progresso realizado pelo Nordeste nos últimos anos, sua economia está hoje mais vulnerável a uma sêca de proporções do que no passado. E explica: "A maior vulnerabilidade aos efeitos da sêca é conseqüência principalmente do aumento da população ocupada no setor lavoura e, especialmente, em cultivos de subsistência afetados pela estiagem. Em 1958 havia cêrca de 3.700 .000 pessoas em cultivos sujeitos a sêca. Estima-se que em 1969 haverá cêrca de 4.400 .000 pessoas empregadas naquelas atividades."

3) A capacidade dos Estados maiores de absorverem maciçamente os incentivos fiscais não foi ainda neutralizada pelos dispositivos corretores contidos no IV Plano Diretor, como se observa do fato de que, do valor total dos projetos aprovados em 1969, cêrca de $60 \%$ se destinavam a três Estados.

\section{O NORDESTE E O PROGRAMA DE INTEGRAÇÃO NACIONAL}

A comemoração dos 10 anos da SUDENE e, principalmente, a volta da sêca levaram o Govêrno a uma tomada de posição em relação às perspectivas do desenvolvimento do Nordeste. A viagem do Presidente Médici ao Nordeste determinou a tomada de decisões.

Como é óbvio, o impacto da sêca dramatizou a constatação de que na década de 60 não se havia constituído uma infraestrutura agrícola na região. Permanece pràticamente intato o problema da região semi-árida, abrangendo o sertão e o litoral setentrional, com cêrca de $62 \%$ da área e $48 \%$ da população do Nordeste, ou seja, na ordem de 13 milhões de habitantes. No quadro limitado de soluções que se havia aceito, permanecia a equação impossível de como resolver, em definitivo, o problema do Nordeste sem a transformação da sua agricul- 
tura e sem a sua integração com o Planalto Central e a Amazônia.

Essencialmente, o problema reside em ter, naquela faixa semi-árida, uma base física que, em condições de inverno normal, conduz à baixa produtividade por hectare nas lavouras da região. E, dada a elevada densidade populacional, que tende a agravar-se ante a elevada taxa de crescimento demográfico, leva à muito baixa produtividade por trabalhador. Baixa produtividade que só se evitaria através de alta capitalização, no estilo de Israel, cujo exemplo indica uma solução técnica para - problema da agricultura de regiões semi-áridas, mas não a solução econômica para um país, como o Brasil, que dispõe de amplas alternativas de terras férteis, nas zonas úmidas do Nordeste e em outras áreas.

O círculo vicioso se fecha quando recordamos que a ausência de uma agricultura dinâmica e de mercado torna não sustentável o processo de industrialização. E impede a solução do problema do emprêgo, numa economia em que a indústria responde por apenas $15 \%$ da produção regional, cabendo $35 \%$ à agricultura e $50 \%$ ao setor de serviços. E impede ainda a solução do problema de desigualdade de renda e da vulnerabilidade da economia regional às sêcas, como, aliás, assinalou o ilustre Governador da Paraíba, em entrevista a revista de São Paulo, quando preconizava um programa de irrigação e eletrificação rural no Nordeste.

Dessa perspectiva de impasse para o desenvolvimento do Nordeste é que nasceu o Programa de Integração Nacional, estabelecido pelo Decreto-lei no 1.106, de 1970, no montante de $\mathrm{Cr} \$ 2.000$ milhões, para o periodo 1971/1974. Essencialmente, pela construção da Transamazônica e da Cuiabá-Santarém, ao lado do programa de colonização a elas associado, o Programa estabelece um sistema de vasos comunicantes entre - Nordeste e a Amazônia; e objetiva promover a construção da infra-estrutura agrícola do Nordeste, através do Plano de Irrigação do Nordeste, destinado ao aproveitamento de vales úmidos e à elevação de produtividade da faixa semi-árida. Nêle se inclui a primeira fase de um programa de desenvolvimento 
do Vale do São Francisco, que irá constituir uma das mais importantes realizações da próxima década, no quadro da região.

Nascido para atender ao Nordeste, o Programa de Integração Nacional representa, para o desenvolvimento da região, uma estratégia muito superior ao caminho limitado que se vinha seguindo, porque permite acrescentar as duas linhas de atuação indispensáveis à superação do impasse referido: a da integração setorial dentro do Nordeste, passando a agricultura a constituir o suporte da industrialização e o elemento de resistência ao efeito das sêcas; e a da integração espacial, pela articulação com o Planalto Central e a Amazônia. Assim se criam condições para absorver na região, na faixa semi-árida e nos vales úmidos, com níveis de produtividade aceitáveis, a maior parcela possivel de população; e aos excedentes se oferece a opção - pois de opção se trata, realmente - de um deslocamento, racional e organizado, para os programas de colonização na nova fronteira econômica.

Ao mesmo tempo em que se procurou dotar o Nordeste de uma estratégia de desenvolvimento que superasse as limitações da fase anterior, definiu-se, para o Programa de Integração Nacional, esquema financeiro que lhe permitisse atender aos dois condicionantes colocados pela programação geral de Govêrno, ou seja: não prejudicar a meta global de crescimento do PIB, fixada em um nivel mínimo de 7 a $9 \%$ ao ano, e ser compatível com a política de redução gradativa da taxa de inflação. Ao estabelecer o seu financiamento através da parcela correspondente a $30 \%$ dos incentivos fiscais à SUDENE, SUDAM, Pesca, Reflorestamento e Turismo, tem o Govêrno o firme propósito de evitar a redução dos recursos destinados ao desenvolvimento do Nordeste e, em particular, ao seu programa de industrialização. $E$ isso será evitado.

O Quadro III mostra como, efetivamente, a nova estratégia para o Nordeste, fundada no Programa de Integração e nos projetos complementares que a êle se irão associar, no atual Govêrno, significará uma saída de recursos, do Nordeste, de Cr\$1.200 milhões, correspondentes a $30 \%$ dos incentivos fiscais da SUDENE, no período 1971/1974 -(a preços de 1970); mas haverá uma entrada de aplicações na região, nos programas já citados, da ordem de Cr $\$ 1.800$ milhões, se houver a aplicação de Cr\$1.100 milhões no Programa de Irrigação. Ou seja, muito acima do valor das saidas, significando uma entrada liquida de Cr\$ 600 milhões. 
QUADRO III

Nordeste - Recursos para o PIN e Aplicaçōes

Provenientes do PIN e Programas Conexos

$1971 / 1974$

Cr\$ milhões de 1970

RECURSOS DO

NORDESTE PARA

$O$ PIN

APLICAÇÕES NO NORDESTE

1. Plano de Irrigação do Nordeste (inclusive

o Programa do São Francisco) ........ 1.100

1.1 - São Francisco

1.2 - Parnalba

1.3 - Jaguaribe

1.4 - Paraíba

1.5 - Moxotó

1.6 - Rio das Contas

1.7 - Outros

2. Pecuária e outros projetos agrícolas novos (BID, BIRD etc.) .................

3. Outros projetos do PIN ..............

4. Novos projetos de apoio ao Nordeste (Habitação, Saneamento, Indústria, Transportes)

1. $30 \%$ dos Incentivos Fiscais ....... 1.200

TOTAL $\ldots \ldots \ldots \ldots \ldots \ldots \ldots \ldots \ldots \ldots \ldots \ldots$

A verdade é que a construção da primeira fase da Transamazônica e da Cuiabá-Santarém, estimada na ordem de Cr\$ 400 milhões, poderá ser financiada apenas com a parcela de $30 \%$ dos incentivos fiscais da SUDAM, estimada em Cr\$ 460 milhões. Para o programa de colonização, ficarão disponíveis os $30 \%$ da Pesca, Reflorestamento e Turismo, estimados em Cr\$330 milhões, além de outras fontes de recursos (de órgãos dos Ministérios do Interior e da Agricultura, de fontes externas, de outras fontes do PIN).

Assegurou-se, por outro lado, que a industrialização continuará sendo fortalecida. Pelos dados de 1969, a indústria contou com menos de $75 \%$ do valor total dos projetos aprovados pela SUDENE, e com $50 \%$ dos aprovados pela SUDAM. Isso significa que, no Nordeste, a Agricultura, com participação crescente, já se estava aproximando dos $30 \%$, avançando para, em breve, estar na ordem da parcela ora destinada ao Programa de Integração. Poder-se-á, agora, concentrar os $70 \%$ remanescentes no setor de indústria, que, assim, continuará recebendo, globalmente, aproximadamente o que iria tender a receber nos próxi- 
mos anos, com o benefício talvez, de certa elevação da prioridade média dos projetos aprovados. Ao lado disso, o BNDE irá acelerar a sua contribuição ao desenvolvimento do Nordeste, através, principalmente, do financiamento de projetos integrados, com o conjunto petroquímico da Bahia, o de sal-gema de Alagoas e o de potássio de Sergipe, para citar apenas três projetos que somam um investimento total de $\mathrm{Cr} \$ 1.000$ milhões.

O setor agrícola do Nordeste poderá ser melhor atendido fora dos incentivos fiscais, que vinham financiando, salvo exceções, projetos de baixa produtividade, como se infere do fato de que nenhum daqueles projetos recebera, por exemplo, financiamento com recursos próprios do Banco do Nordeste. O desenvolvimento agrícola se fará com recursos do Programa de Integração, com recursos adicionais dos órgãos do Ministério do Interior e de outras fontes, através do plano de irrigação e de aproveitamento de vales úmidos; de financiamento mais amplo através do Banco do Nordeste, que irá expandir a sua atuação nessa área; do BNDE, que está financiando os programas de Centrais de Abastecimento e de estradas vicinais; das políticas de preços mínimos e de disseminação de insumos modernos, pelo Banco do Brasil e outros mecanismos financeiros.

Desejo, na oportunidade, salientar que, em reunião realizada dois dias atrás, com o Ministro da Fazenda, já ficou assegurado o esquema através do qual, pelo orçamento monetário, será o Banco do Nordeste atendido, de modo a não apenas não sofrer redução, mas a continuar expandindo as suas operações, em têrmos reais, nos próximos anos, a uma taxa satisfatória.

\section{APOIO A ACELERAÇÃO DO DESENVOLVIMENTO DO NORDESTE}

A estratégia de desenvolvimento para o Nordeste, na próxima década, deve ter como objetivos básicos o crescimento do produto regional acima de $7 \%$ ao ano; o equacionamento do problema do emprêgo, pela ampliação de oportunidades nas zonas urbana e rural e pela expansão da fronteira agrícola, dentro e fora da região; o equacionamento do problema da região semi-árida, pela elevação da produtividade da mão-de-obra empregada e pela montagem de uma infra-estrutura agrícola resistente às sêcas, significando inclusive a sua transformação em economia de mercado, com a criação de emprêsas agricolas; e o encaminhamento do problema social, reduzindo as dramáticas disparidades de renda e preparando o homem nordestino para o trabalho a níveis razoáveis de eficiência. 


\section{QUADRO IV}

Apoio aos Setores Básicos do Nordeste

I - INDÚSTRIA

1.1 - Concentração dos Incentivos Fiscais (70\% remanescentes)

1.2 - Aperfeiçoamento dos Critérios de Avaliação, para corrigir distorções

1.3 - Recursos adicionais do BNDE e outros bancos oficiais

II - AGRICULTURA

II.1 - Recursos do Programa de Integração Nacional (Plano de Irrigação, colonização de vales úmidos)

II.2 - Maior participação nos investimentos da SUDENE, DNOCS e outros órgãos do Ministério do Interior e do Ministério da Agricultura

II. 3 - Novos programas do BNB (recursos do BID, BIRD)

II. 4 - Programa de Pecuária (BNB)

II.5 - Programa de Centrais de Abastecimento

II. 6 - Preços mínimos, insumos modernos (BB)

II.7 - Pesquisa agrícola

Aquela estratégia deverá desenvolver pelo menos as seguintes frentes de atuação:

I - Continuação do programa acelerado de investimentos do Govêrno Federal, através dos Ministérios com atuação destacada na área (Interior, Transportes, Minas e Energia, Educação, Saúde), num total de $\operatorname{Cr} \$ 4.800$ milhões, no período 1970/1973 (a preços de 1970); e do programa de transferências da União para os Estados e Municípios do Nordeste, através do Fundo de Participação e do Fundo Especial, no montante de Cr\$2.000 milhões no mesmo período.

II - Continuação do programa de industrialização, que deverá absorver a quase totalidade dos incentivos fiscais, estimados em Cr\$2.800 milhões no período 1971/1974. Em colaboração com a SUDENE, já se está preparando a programação do fluxo de caixa nos próximos anos, a fim de assegurar pleno atendimento aos projetos prioritários para a Indústria do Nordeste.

III - Fortalecimento da Agricultura da região, através dos instrumentos já indicados, e, principalmente, da primeira etapa de implantação do Plano de Irrigação do Nordeste, já incluída no Programa de Integração Nacional, com investimentos previstos de $\operatorname{Cr} \$ 1.100$ milhões até 1974 , num total de 50 projetos prioritários, para uma área irrigada da ordem de $100.000 \mathrm{ha}$ em comparação com os 12.000 ha atuais. 
IV - Fortalecimento e reorganização da agroindústria canavieira, através do GERAN, com execução imediata dos projetos de racionalização já elaborados.

V - Integração da política de fortalecimento da Agricultura do Nordeste com o Planalto Central e a Amazônia, no contexto do Programa de Integração Nacional, tendo como principal instrumento a construção da Transamazônica, com a simultânea implantação do programa de colonização e reforma agrária ao longo de sua diretriz.

$O$ apoio do Govêrno Federal a essas linhas de atuação pode ser consubstanciado num elenco de 22 projetos prioritários para execução no Nordeste, através dos diferentes Ministérios, no mandato do atual Govêrno. Êsse elenco, já definido e agora com instruções do Presidente Médici para aceleração de sua execução, figura no Quadro V.

\section{QUADRO V \\ Projetos Prioritários do Govêrno Federal no Nordeste $1970 / 1973$}

Cr\$ milhöes de 1970

\section{AGRICULTURA - ABASTECIMENTO}

1) Plano de Irrigação do Nordeste - $\mathrm{Cr} \$ 1.500$ milhões

2) Centrais de Abastecimento de Recife, Salvador, Fortaleza, Aracaju, Maceió - Cr\$ 70 milhöes.

3) Terminal Açucareiro do Recife - Cr\$ 40 milhōes.

4) Racionalização de Agroindústria Canavieira - Cr\$ 120 milhōes.

5) Projeto de Pecuária e outros Projetos agricolas do BNB com recursos externos - Cr\$250 milhöes.

6) Eletrificação Rural - Cr\$85 milhões.

INDÚSTRIA E MINERAÇÃO

7) USIBA - Cr\$ 190 milhões.

8) Conjunto Petroquimico da Bahia - $\mathrm{Cr} \$ 635$ milhōes.

9) Soda Cáustica (Sal-gema, Alagoas) - Cr\$ 230 milhões.

10) Projeto de Amônia - $\mathrm{Cr} \$ 100$ milhōes.

11) Projeto de Cobre - Cr\$320 milhões.

12) Produção de Fibra e Fios Poliestéricos e Acrílicos - $\mathrm{Cr} \$ 135$ milhőes.

13) Projeto de Potássio, de Sergipe - Cr\$ 450 milhões.

ENERGIA, TRANSPORTES, COMUNICAÇŌES

14) Usinas de Moxotó e Paulo Afonso IV - Cr\$2 241 milhöes.

15) Expansão da COHEBE - Cr\$ 18 milhöes. 
16) Exploração e Produção de Petróleo - Cr\$2.240 milhões.

17) Consolidação da Rêde Rodoviária Básica do Nordeste - Cr\$ 928 milhões.

18) Tronco Nordeste de Microondas: Belo Horizonte - Recife - Fortaleza; Fortaleza - São Luis - Belém - Cr\$ 100 milhőes.

EDUCAÇÃO, SAÚDE, SANEAMENTO, HABITAÇÃO

19) Programa de Ginásios Orientados para o Trabalho - Cr $\$ 35$ milhões.

20) Operação Escola - Cr\$ 25 milhões.

21) Programa de Saneamento (Agua e Esgotos) - Cr\$ 250 milhões.

22) Habitação - Cr\$150 milhões.

\section{SENTIDO E GRANDEZA DO PROGRAMA DE INTEGRAÇÃO}

Poucas vêzes, em nossa vida de homens públicos, teremos tido a oportunidade de tomar decisão em assunto de dimensão e impacto do Programa de Integração Nacional. Sua significação essencial pode ser sintetizada nos seguintes pontos:

1) O Brasil empurra a fronteira econômica para as margens do Rio Amazonas, crescendo para dentro, realizando, em grande escala e numa área com importantes manchas de terras férteis, o que a Belém-Brasília e outras rodovias de penetração vinham fazendo em pequena escala, assistemàticamente e em áreas menos férteis.

2) Integram-se a estratégia de ocupação econômica da Amazônia e a estratégia de desenvolvimento do Nordeste, rompendo um quadro de soluções limitadas para ambas as regiőes.

Não seria correto reduzir a significação da Transamazônica pela comparação com outras rodovias já em construção na Amazônia, mas de sentido apenas regional, ainda quando associadas a programas de colonização. Pelas condições mais favoráveis a um programa de colonização e reforma agrária; pelas perspectivas de projetos de exploração mineral; pela sua diretriz de sentido transversal aos vales; pela sua localização, no limite com o Planalto Central e o Nordeste, sòmente a Transamazônica (associada à Cuiabá-Santarém) tem a função de integração nacional, criando o sistema de vasos comunicantes entre o Centro, a Amazônia e o Nordeste.

Da mesma forma, não seria válido avaliar a Transamazônica em têrmos estritos de rentabilidade econômica, embora seja êste o critério normal e indispensável de definição de prioridades em um Programa de Transportes. O critério de avaliação, no caso, deve ser o da produtividade marginal social do em- 
preendimento, considerando todos os seus efeitos, diretos e indiretos, econômicos, sociais e políticos, como instrumento essencial do Programa de Integração Nacional, que, como assinalado, representa um enfoque integrado das estratégias para as duas regiões, a fim de eliminar as limitações em que o enfoque de estratégias isoladas importava.

Igualmente, não tem qualquer procedência a referência feita, há dias, de que a Rodovia Transamazônica se destinaria a beneficiar emprêsa estrangeira envolvida em projeto de mineração na região de Marabá. Pura e simplesmente, a Cia. Vale do Rio Doce detém $51 \%$ das ações daquela emprêsa, que, de fato e de direito, constitui, pois, emprêsa nacional. Para não mencionar o fato óbvio de que o referido projeto foi aprovado pelos seus próprios méritos, como de interêsse para o País, numa altura em que não havia, ainda, qualquer decisão em relação à Transamazônica.

3) Criam-se condições para a incorporação, à economia de mercado, no sentido da capacidade de produção e no sentido da aquisição de poder de compra monetário, de amplas faixas de população antes dissolvidas na economia de subsistência, condenada à estagnação tecnológica e à perpetuação de um drama social intolerável.

4) Criam-se condições para a efetiva transformação de Agricultura da região semi-árida do Nordeste.

5) Reorientam-se as emigrações de mão-de-obra do Nordeste, em direção aos vales úmidos da própria região e à nova fronteira agrícola, evitando-se o seu deslocamento no sentido das áreas metropolitanas superpovoadas do Centro-
Sul.

6) Assegura-se o apoio do Govêrno Federal ao Nordeste, para garantir um processo de industrialização tendente à autosustentação e realizar as metas de desenvolvimento progra-
madas.

São essas características que me permitem a liberdade de, concluindo esta exposição, transmitir à consciência dos homens públicos que militam nesta Casa, e estou certo de que são todos que a ela pertencem, um apêlo em favor de um voto de confiança no Brasil, após o diálogo esclarecedor que aqui se tem desenvolvido, levando o seu apoio ao Programa de Integração Nacional. Confiança no Brasil, principalmente, por parte daqueles que, filhos do Nordeste, possam ter dúvidas quanto a certos aspectos de sua formulação, na convicção de que, co- 
mo procuramos salientar, o Programa de Integração é, antes de tudo, a solução corajosa, árdua, necessária, para o próprio desenvolvimento do Nordeste. É importante não minimizar as dificuldades de execução do Programa, seja na construção da Transamazônica e no programa de colonização, principalmente quanto à assistência financeira, técnica e social, a ser provida aos ocupantes das novas áreas; seja no plano de irrigação do Nordeste, campo em que o Brasil ainda tem tradição insuficiente. Mas é preciso mostrar que, para um Govêrno digno do povo, para um Govêrno digno do Brasil - e esta Casa é, antes de tudo, um dos Podêres da União - , êsse desafio tem de ser enfrentado.

Aos meus amigos do Nordeste, direi, ainda, que o Programa de Integração Nacional não é, sòzinho, suficiente para construir o nôvo Nordeste. Ter uma estratégia de desenvolvimento dotada de poderosos instrumentos é indispensável. E é muito. Será mais se essa estratégia encaminhar a solução do problema social da região. Mas é, adicionalmente, necessário que se dê a essa estratégia a dimensão política indispensável - política, no sentido de criar, na região, estruturas sociais e políticas abertas, favoráveis à renovação de valôres; política, no sentido de lideranças capazes de realizar a mobilização da comunidade para o desenvolvimento; política, no sentido de que os governos do Nordeste, os atuais e os novos, realizem o esfôrço próprio que deve ser o ponto de partida para o desenvolvimento da região, engajando-se firmemente no propósito de mudar o Nordeste. Para essa mudança, que em grande medida tem dimensão política, nenhum papel seria mais importante que o dos parlamentares do Nordeste, de tôdas as procedências e agremiações.

Mudança que tem aquêle sentido definido pelo Presidente Garrastazu Médici ao concluir o seu discurso no Nordeste:

"E hoje, nesta cidade do Recife, perante governadores e ministros, pensando no povo, particularmente no povo nordestino, quero dizer que não me sinto com podêres e dons para fazer milagres, mas tenho firmeza, confiança e decisão, para proclamar à Nação inteira que, com a ajuda de todos os brasileiros e com a ajuda de Deus, o Nordeste afinal haverá de mudar." 


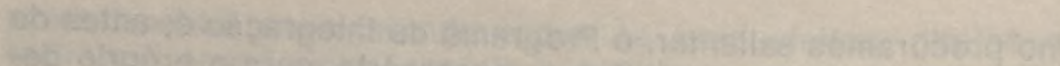

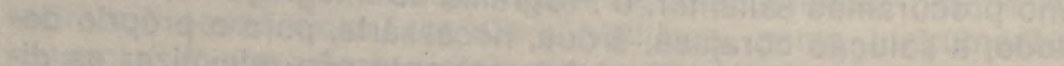

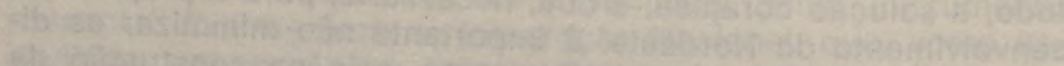

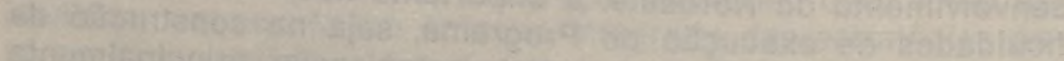

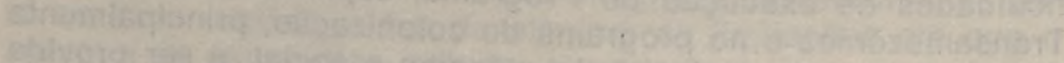

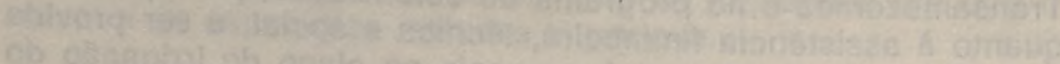

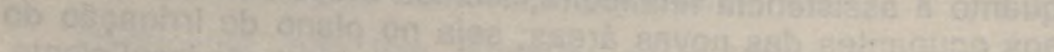

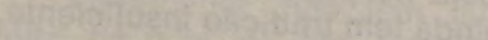

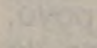

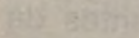

$30^{2}$
3

nas

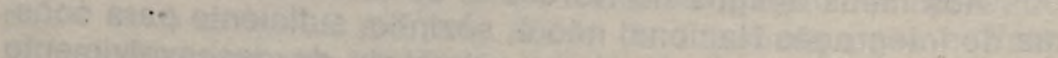

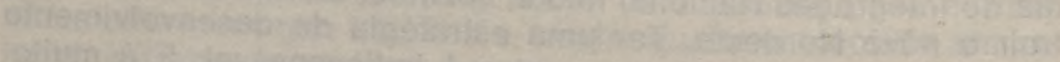

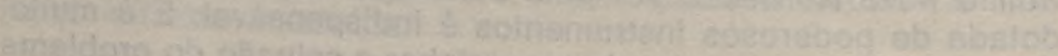

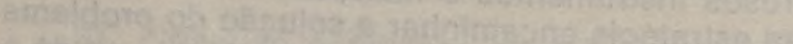

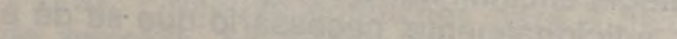

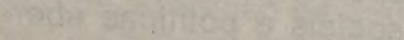

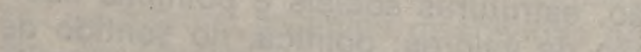

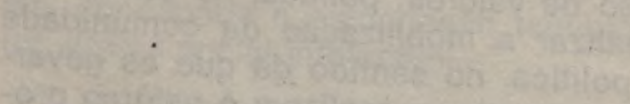

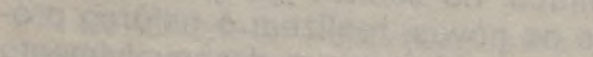

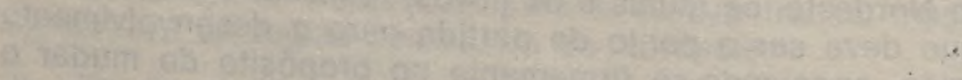

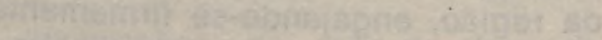

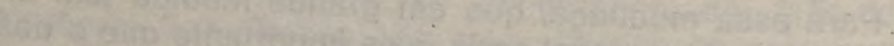

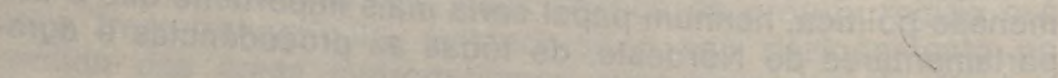

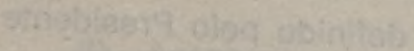

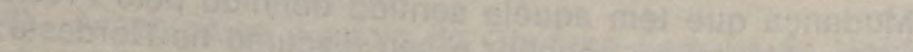
6.

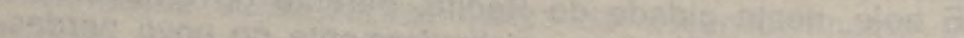

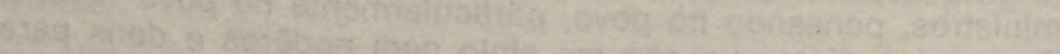

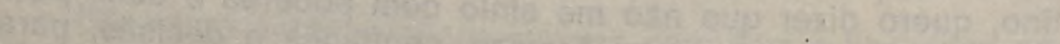

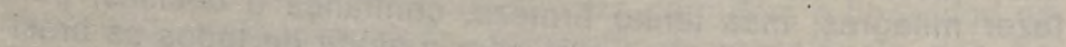

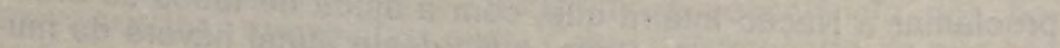

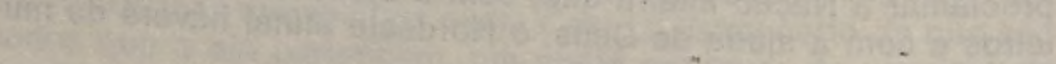

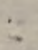

